\title{
Distribution of alpha-fetoprotein in fetal plasma and in amniotic and allantoic fluids of the pig*
}

\author{
A. J. Luft, P. C. W. Lai, H. A. Robertson $\dagger$, N. R. Saunders $\ddagger$ and \\ F. L. Lorscheider
}

Department of Medical Physiology, Faculty of Medicine, University of Calgary, Calgary, Alberta, Canada, T2N $1 N 4$; $\dagger$ Animal Research Centre, Agriculture Canada, Ottawa, Ontario, Canada KIA OC6; and $\ddagger$ Department of Physiology, University College, London WC1E 6BT, U.K.

\begin{abstract}
Summary. The concentration of AFP in the plasma of fetal pigs was highest in early gestation (Days 15-30) and declined with advancing gestation. This pattern was comparable to those observed in other mammals with similar lengths of gestation. In contrast, allantoic and amniotic fluid AFP concentrations were highest during the middle third of gestation but these concentrations were much lower than those in fetal plasma throughout gestation. The allantois appears to be a significant distribution space for AFP in early gestation.
\end{abstract}

\section{Introduction}

Alpha-fetoprotein (AFP) is a major serum protein found in the fetuses of a number of mammals (Gitlin \& Boesman, 1967). The levels of AFP in various fluid spaces in the conceptus have been studied in man (Seppala, 1975), cattle (Smith, Lai, Robertson, Church \& Lorscheider, 1979), sheep (Lai, Mears, Van Petten, Hay \& Lorscheider, 1978) and rats (Lai, Forrester, Hancock, Hay \& Lorscheider, 1976). Fetal blood AFP in pigs has also been determined at various stages of gestation (Karlsson, 1972; Stone, 1981; Cavanagh et al., 1982). However, understanding of the distribution of porcine AFP in other fetal compartments as a function of gestational age is limited because determinations in allantoic and amniotic fluids have only been made at Day 40 of gestation (Stone \& Maurer, 1979). The purposes of this investigation were to determine the level of AFP in amniotic and allantoic fluids of fetal pigs throughout gestation and to compare such findings with those of other species.

\section{Materials and Methods}

Animals. Unless otherwise stated, all specimens were collected at the time of slaughter from 26 pregnant sows. Each conceptus was removed from the uterus and fluid specimens were aspirated from allantoic and amniotic sacs. Fetal blood was collected from the umbilical artery. Specimens from very early gestation (Days 15-30) were collected as described above but at laparotomy under halothane general anaesthesia. Gestational ages of all fetuses were calculated from planned mating dates.

* Reprint requests to Dr F. L. Lorscheider, Department of Medical Physiology, Faculty of Medicine, University of Calgary, Calgary, Alberta, Canada T2N 1 N4. 
Radioimmunoassay. AFP concentration was determined by radioimmunoassay using purified porcine AFP and rabbit anti-porcine AFP as described by Cavanagh et al. (1982). This assay used an antiserum titre of $1: 1000$ and incorporated $8 \%$ polyethylene glycol as a secondary precipitant. The lower limit of assay sensitivity was $30 \mathrm{ng} / \mathrm{ml}$. The intra- and inter-assay variability expressed as coefficients of variation were $2 \cdot 4 \%(n=18)$ and $9.4 \%(n=15)$ respectively.

\section{Results}

Fetal plasma AFP was highest in early gestation with concentrations of approximately $9 \mathrm{mg} / \mathrm{ml}$ during the first third of gestation. The concentration of AFP declined gradually to $<2 \mathrm{mg} / \mathrm{ml}$ in the last third of gestation (Text-fig. la).

The concentration of AFP in allantoic fluid was lowest in early gestation (Days 15-30), reached a peak $(0.34 \mathrm{mg} / \mathrm{ml})$ in mid gestation and declined thereafter until term (Text-fig. $1 \mathrm{~b})$. The values remained much lower than those in fetal plasma throughout gestation.
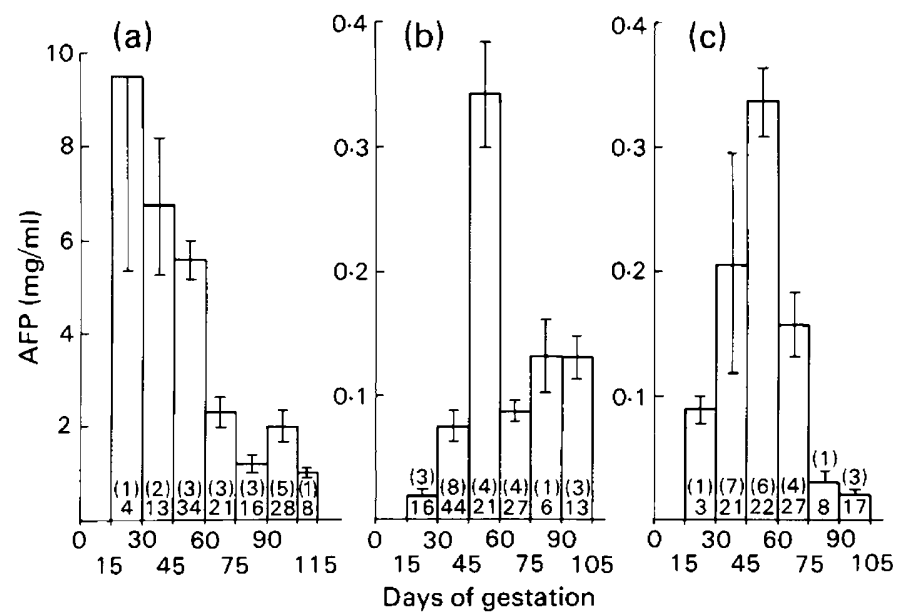

Text-fig. 1. Concentration of porcine AFP in (a) fetal plasma, (b) allantoic fluid and (c) amniotic fluid. Values are mean \pm s.e.m. for the number of fetuses indicated in each column. The value in parentheses indicates the numbers of litters.

In amniotic fluid the changes in concentration of AFP were similar to those in allantoic fluid, being lowest in early gestation, reaching a peak of $0.34 \mathrm{mg} / \mathrm{ml}$ in mid-gestation and declining thereafter until term (Text-fig. 1c).

\section{Discussion}

AFP appears to be a major plasma protein during early gestation in the fetal pig. The plasma level declines with advancing gestation. This pattern is similar to that in other domestic animals, such as cattle (Smith et al., 1979) and sheep (Lai et al., 1978), with relatively long gestational periods. However, this pattern is in contrast to those observed in species with short gestational periods, such as the rat (Lai et al., 1976) and rabbit (Branch, 1972), in which fetal serum AFP peaks in late gestation. The mechanisms responsible for activating and suppressing AFP synthesis have not yet been fully elucidated, but in all species so far studied, including the pig, fetal blood AFP concentration decreases before birth. 
Amniotic fluid AFP concentration in the fetal pig peaks in mid-gestation. This pattern is similar to that in sheep which has a comparable length of gestation (Lai et al., 1978) but differs from that in cows in which pregnancy is longer and AFP peaks in the first third of pregnancy (Smith $e t$ al., 1979). Amniotic fluid dynamics are a function of numerous exchanges within the various fetal and maternal compartments (Seeds, 1980; Mears, Lai, Van Petten \& Lorscheider, 1981), and further study on the significance of variation in amniotic fluid AFP levels of pigs would require data on changes in volumes of the various fetal fluid spaces as a function of gestation and tracer kinetic studies using labelled AFP.

Allantoic fluid AFP concentration in the fetal pig peaks in mid-gestation with a pattern very similar to that found in amniotic fluid, suggesting a common source of AFP as we have previously discussed (Smith et al., 1979). The total content of AFP in each fetal compartment was calculated using volume data from Arthur (1969) and the concentrations of AFP from the present study. In the first month of life, allantoic fluid contained $2.6 \mathrm{mg}$ AFP, fetal plasma contained $2.0 \mathrm{mg}$ AFP and amniotic fluid contained $<1.8 \mathrm{mg}$ AFP. Therefore, the allantois is a significant distribution space for AFP in early gestation.

This research was supported by grants from The Alberta Children's Hospital Foundation, The University of Calgary, The Wellcome Trust-U.K., and the North Atlantic Treaty Organization. The assistance of K. E. Hartin in obtaining some specimens is gratefully acknowledged.

Animal Research Centre contribution No. 1206.

\section{References}

Arthur, G.H. (1969) The fetal fluids of domestic animals. J. Reprod. Fert., Suppl. 9, 45-52.

Branch, W.R. (1972) The ontogeny of alpha-foetoprotein in the foetal and neonatal rabbit, and its experimental induction in adult rabbits. Int. J. Cancer 10, 451-457.

Cavanagh, M.E., Cornelis, M.E., Dziegielewska, K.M., Luft, A.J., Lai, P.C. W., Lorscheider, F.L. \& Saunders, N.R. (1982) Proteins in cerebrospinal fluid and plasma of fetal pigs during development. Dev. Neurosci. 5, 492-502.

Gitlin, D. \& Boesman, M. (1967) Fetus-specific serum proteins in several mammals and their relation to human $\alpha$-fetoprotein. Comp. Biochem. Physiol. 21, 327-336.

Karlsson, B.W. (1972) $\alpha$-Foetoprotein in serum of the developing foetus. Life Sci. 11, 169-176.

Lai, P.C.W., Forrester, P.I., Hancock, R.L., Hay, D.M. \& Lorscheider, F.L. (1976) Rat alpha-fetoprotein: isolation, radioimmunoassay and fetal-maternal distribution during pregnancy. $J$. Reprod. Fert. 48, 1-8.

Lai, P.C.W., Mears, G.J., Van Petten, G.R., Hay, D.M.
\& Lorscheider, F.L. (1978) Fetal-maternal distribution of ovine alpha-fetoprotein. Am. J. Physiol. 235, E27-E31.

Mears, G.J., Lai, P.C.W., Van Petten, G.R. \& Lorscheider, F.L. (1981) Fetal-maternal transfer and catabolism of ovine ${ }^{125} \mathrm{I}$-labelled $\alpha$-fetoprotein. Am. J. Physiol. 240, E191-E196.

Seeds, A.E. (1980) Current concepts of amniotic fluid dynamics. Am. J. Obstet. Gynec. 138, 575-586.

Seppala, M. (1975) Fetal pathophysiology of human alpha-fetoprotein. Ann. N.Y. Acad. Sci. 259, 59-73.

Smith, K.M., Lai, P.C.W., Robertson, H.A., Church, R.B. \& Lorscheider, F.L. (1979) Distribution of alpha ${ }_{1}$ fetoprotein in fetal plasma, allantoic fluid, amniotic fluid and maternal plasma of cows. J. Reprod. Fert. 57, 235-238.

Stone, R.T. (1981) In vitro liver synthesis and serum levels of alpha-fetoprotein and albumin in the fetal pig. Biol. Reprod. 24, 573-580.

Stone, R.T. \& Maurer, R.R. (1979) Radioimmunoassay of porcine alpha-fetoprotein. Biol. Reprod. 20, 947953.

Received 27 July 1983 